\title{
The Impact of Age on Cochlear Implant Performance
}

\author{
Brian Schwab, Michele Gandolfi, Erica Lai, Erin Reilly, Lorie Singer, Ana H. Kim \\ Department of Otolaryngology, New York Eye and Ear Infirmary of Mount Sinai, New York, USA \\ Email: bschwab@nyee.edu
}

Received 21 July 2015; accepted 28 August 2015; published 31 August 2015

Copyright (C) 2015 by authors and Scientific Research Publishing Inc.

This work is licensed under the Creative Commons Attribution International License (CC BY). http://creativecommons.org/licenses/by/4.0/

(c) (i) Open Access

\begin{abstract}
Objective: Cochlear implantation is the emerging treatment of choice for severe and profound sensorineural hearing loss, yet there are conflicting data on outcomes in adults. There is significant variability in the literature concerning the exact effect of age on cochlear implant outcomes. We sought to evaluate the outcomes of cochlear implant performance stratified by age. Study Design: Retrospective review. Methods: Audiologic preoperative and postoperative evaluation consisted of word recognition scores (Consonant-Nucleus-Consonant). Complications were retrospectively collected after each cochlear implantation. A sub-analysis was performed comparing patients implanted at a younger ( 21 - 64 years) and older (65 and above) age. Results: A total of 240 patients were evaluated. Patients experienced a significant improvement in audiologic performance as seen with word recognition scores $(p<0.00001)$. The mean post-implant score was $44.6 \%$ (at 3 months) and $53.5 \%$ (at 24 months) at $50 \mathrm{~dB}$ compared to average pre-implantation aided score of $6 \%$. There was no significant difference between postoperative performances in younger versus older patient groups. Multiple regressions showed no correlation with duration of deafness at time of implantation or age and performance. There was no significant difference in performance based on side of implantation. Conclusion: This is one of the largest series to date on hearing outcomes in adults who receive a cochlear implant. No statistical differences were noted between the younger and older groups or based on side of implantation. The audiologic benefit in the adult population is clearly demonstrated.
\end{abstract}

\section{Keywords}

Cochlear Implantation, Age, Duration of Deafness

\section{Introduction}

According to the World Health Organization, 328 million adults have disabling hearing loss. Globally, hearing

How to cite this paper: Schwab, B., Gandolfi, M., Lai, E., Reilly, E., Singer, L. and Kim, A.H. (2015) The Impact of Age on Cochlear Implant Performance. International Journal of Otolaryngology and Head \& Neck Surgery, 4, 329-337.

http://dx.doi.org/10.4236/ijohns.2015.45056 
loss is the third leading cause of disability [1]. The demand for treatment is high, and for some patients, traditional methods of amplification are no longer sufficient. Cochlear implantation (CI) is the emerging treatment of choice for severe and profound sensorineural hearing loss, yet there are conflicting data on outcomes in adults [2]. There is significant variability in individual outcomes and benefits, and little data exist regarding the exact effect of age on CI outcomes. With the increasing prevalence of hearing loss, understanding patient outcomes after $\mathrm{CI}$ in adults is imperative.

A number of different factors have been suggested as having prognostic value for implantation benefit, and several predictive models have been designed [3]-[5]. Duration of deafness has been quoted as being the most important prognostic indicator with an inverse relationship to speech performance after implantation. It has been postulated that this may be a result of neuronal reorganization in favor of visual processing secondary to auditory deprivation [6]. Leung et al. found that a shorter percentage of life spent with hearing loss and residual speech recognition carried a greater predictive value in determining postoperative performance than age [7]. Numerous studies have corroborated the prognostic value of shorter duration of deafness and improved outcome [8]-[10]. Yet, there have been other papers proposing that these factors are not exclusively predictive of word recognition scores post cochlear implantation [11]. Though duration of deafness seems to be one potential influencing component for post-implant outcomes, the literature advocates that many factors may potentially influence an individual's speech understanding with a CI. For example, Green et al. reported duration of deafness to be an independent predictor of performance, accounting for $9 \%$ of the variability in a retrospective study examining 117 postlingually-deaf patients [12]. They concluded that, apart from duration of deafness, “Other factors must influence implant performance”.

Furthermore, the relationship between duration of deafness and age has not been thoroughly investigated to the extent of providing a definitive conclusion. A study by Roberts et al. found that older patients significantly improved their speech recognition abilities after implantation but to a lesser degree than younger recipients [13]. This was confirmed by Lin et al. who reported that the magnitude of gain in the speech scores was negatively associated with age at implantation. Lin et al. noted that a 60-year old would expect a 75 percentage point improvement in speech scores, compared to a 50 point improvement in an 80-year old adult [14]. These results suggest that elderly recipients do not improve to the extent of their younger counterparts. However, other studies have failed to conclusively demonstrate a direct correlation between age and decreased outcome within the adult population with respect to word scores or pure-tone audiometry [10] [15]. Evidence to the contrary by Alice et al., for example, showed there was no statistical difference in improvement between older and younger age groups [16].

This study seeks to shed further light on the body of research regarding CI performance in adults. It was hypothesized that older participants would show significant improvement in hearing outcomes after CI, but it was expected that this benefit would be less than in younger CI recipients. Furthermore, it was hypothesized that duration of deafness would have a stronger correlation with hearing outcomes than age at implantation.

\section{Materials and Methods}

\subsection{Study Design}

This is a retrospective review of medical records of postlingually deafened patients greater than 21 years who met the criteria for cochlear implantation from April 1993 to December 2013. Institutional review board exemption was obtained for this study (\#E-13.19). Patients were included in the review of medical records if they were aged 21 and older at time of implantation without cochlear anomalies precluding complete electrode insertion. Exclusion criteria included any patient failing to perform standardized testing through one year postoperatively. Complications were not considered part of the exclusion criteria. Patients were divided into two groups: "younger" CI recipients were defined as people who underwent cochlear implantation between the ages of 21 and 64 whereas “older” CI recipients underwent surgery after the age of 65.

\subsection{Diagnostic Tests}

All tests were performed in an IAC standard double-wall booth audiometry room under conditions meeting ANSI and ISO standards, including calibration, noise levels, and sounds levels. Speech perception materials were presented preoperatively and postoperatively in the IAC standard double-wall booth. The Consonant- 
Nucleus-Consonant (CNC) test in quiet at $50 \mathrm{~dB}$ was performed pre- and postoperatively. This test was developed to provide lists of monosyllabic words with equal phonemic distribution across lists with each list exhibiting approximately the same phonemic distribution as the English language. When patients performed above 80 percent on CNC testing, AzBio sentence testing in quiet was also tested.

\subsection{Statistical Analysis}

The Mann-Whitney nonparametric U test was used to compare age groups with respect to preoperative SRT and audiological testing data. The Mann-Whitney nonparametric $U$ test was also used to compare groups postoperatively. All reported P-values were calculated as two-sided with a level $<0.05$ being considered statistically significant. Multiple regression was performed for correlation between age, duration of deafness, and CNC score at a given postoperative time period. All statistical analyses were performed using Excel (Microsoft, Redmond, W.A.). A multiple regression model was also used to fit the data to a polymetric equation.

\section{Results}

\subsection{Patient Demographics}

There were 119 patients in the younger age group and 121 patients in the older group. There was a similar gender distribution in the two groups: 65 (54.6\%) were female and 54 (45.4\%) were male in the younger group; 61 (50.4\%) were female and 60 (49.6\%) were male in the older group. The average age of the younger group was 46 (range 21 - 64 years at age of implantation). The average age of the older group of patients was 72 (range 65 - 88 years). The mean duration of hearing loss was 19.3 years \pm 14.2 in the younger group (range $0.2-50.7$ years) and $23.4 \pm 16.6$ years in the older group (range $0.5-63.0$ years). The right ear was implanted in 70 (58.8\%) younger patients and 60 (49.6\%) older patients and the left ear in 47 (39.5\%) younger and 58 (47.9\%) older patients. Five patients were implanted bilaterally ( 2 younger patients and 3 older patients). Of the younger patients, 79 lost their hearing because of idiopathic hearing loss; 18 had familial or genetic hearing loss; 8 had an infectious etiology; 7 lost their hearing due to a physical or noise-induced trauma; and 7 had Meniere's disease. Of the older patients, 66 lost their hearing because of idiopathic hearing loss; 28 had familial or genetic hearing loss; 14 lost their hearing due to a physical or noise-induced trauma; 8 had an infectious etiology; and 5 had Meniere's disease. Demographic data is summarized in Table 1. There were very few surgical complications overall, consisting of two wound infections and six patients with dizziness or hyperacusis. Five patients had the implant removed and were re-implanted due to device failure.

Table 1. Patient demographics.

\begin{tabular}{lc}
\multicolumn{1}{c}{ Demographic Characteristics } & 240 \\
\hline Number of patients & $21-88$ \\
& $(56 \pm 16.8)$ \\
Age range at the time of implantation (mean), years & $0-63(21 \pm 15.4)$ \\
Duration of deafness range (mean), years & 114,126 \\
Sex (Male, Female) & $105,130,5$ \\
Side (Left, Right, Bilateral) & 145 \\
Etiology: & 46 \\
Idopathic & 16 \\
Familial or genetic & 21 \\
Infectious & 12 \\
Physical or noise-induced & \\
Meniere's & \\
\hline
\end{tabular}




\subsection{Audiologic Performance and Regression}

There was no significant difference in preoperative speech perception scores between the younger and older groups $(p=0.27)$. The average aided CNC score pre-implant was $5.3 \%$ for the younger group and $6.7 \%$ for the older group.

Average CNC scores in quiet post-implant in the younger age group at 3, 12 and 24 months post-implant were $45.7 \%, 55.2 \%$ and $55.7 \%$, respectively, compared to $43.5 \%, 52.5 \%$ and $51.3 \%$ in the older age group, respectively (Figure 1).

There were no statistical differences in postoperative performance data between the younger and older groups at 3 months ( $p=0.46), 12$ months ( $p=0.86)$, or 24 months $(p=0.64)$. AZBio scores in quiet were also analyzed (results not included in full analysis) to verify results and showed similar trends with no significant differences at 3 months ( $p=0.62), 12$ months ( $p=0.12)$, or 24 months $(p=0.50)$.

At 24 months, multiple regressions showed very weak correlation between age, duration of deafness, and CNC with a multiple regression coefficient of 0.27 . Duration of deafness did not seem to have a significant impact (Figure 2).

For verification, a simple regression and correlation factor were calculated and found to be non-significant. After 24 months, $27.9 \%$ of data points show correlation with age and duration; at 12 months, $16.7 \%$ of data points show correlation with age and duration; at 6 months, $16.27 \%$ of data points show correlation with age and

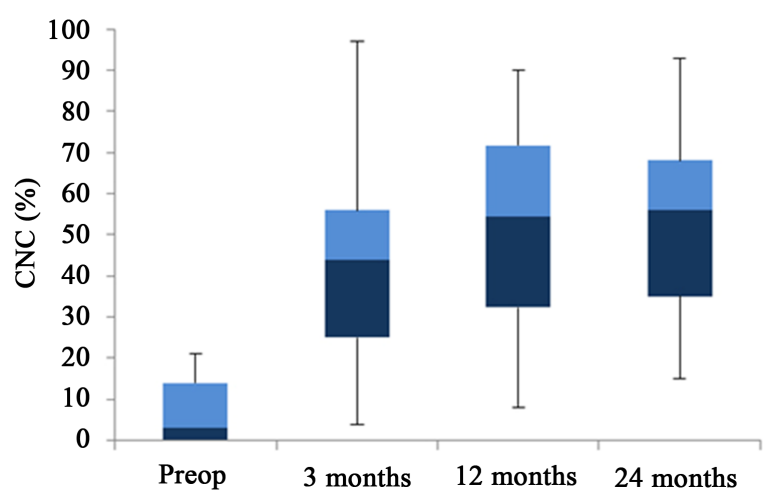

(a)

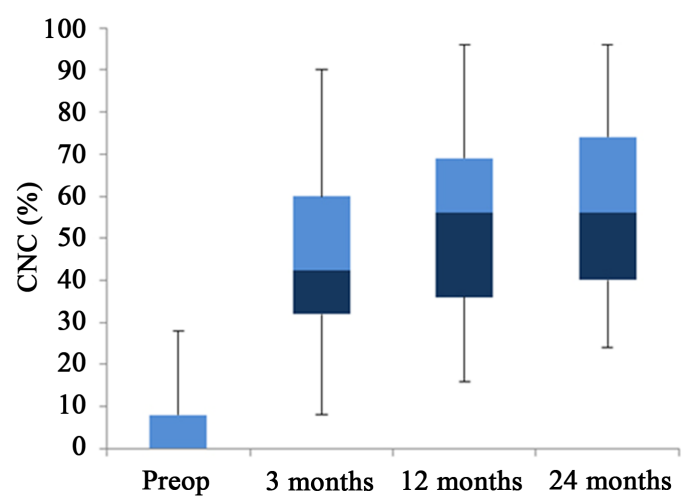

(b)

Figure 1. Box whisker plot of pre- and postoperative CNC speech perception in quiet scores in Younger (a) and Older (b) patients. The light light blue bars represent upper quartile and dark blue the lower quartile. (a) CNC data in younger patients; (b) CNC data in older patients.

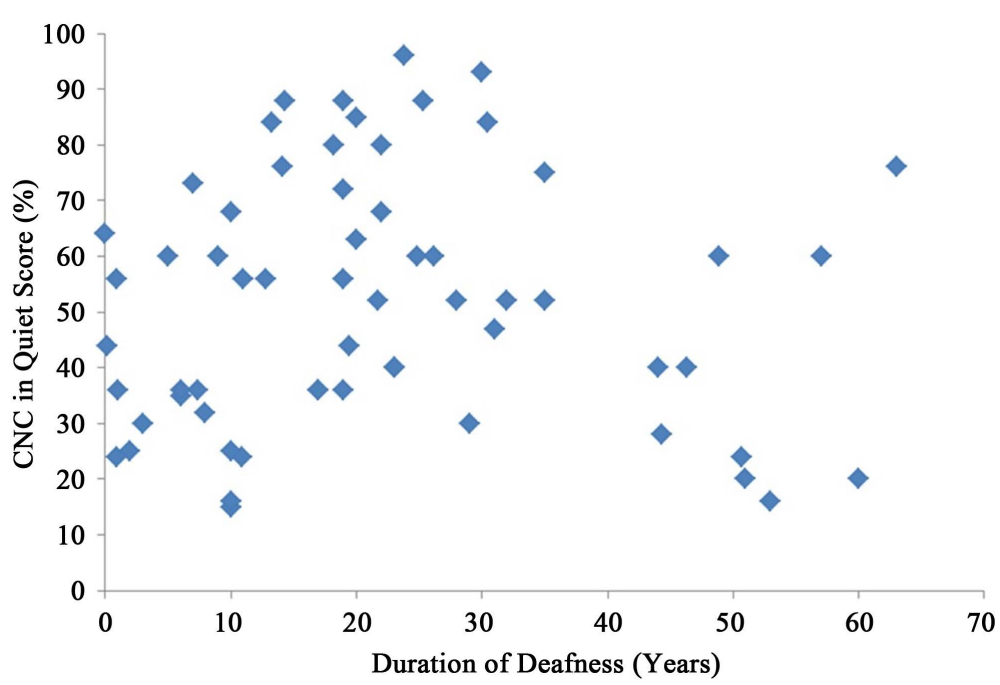

Figure 2. CNC in quiet scores two years after implantation as a function of duration of deafness at the time of implantation. 
duration; at 3 months, $13.9 \%$ of data points show correlation with age and duration (Figures 3(a)-(d)). A multiple regression equation was used to fit the data to a predictive polymetric model and showed an R2 value of 0.931 (Figure 3(e)).

A sub-analysis was performed to examine the differences in postoperative performances in patients implanted in the left ear against patients implanted in the right ear (Figure 4).

There were no significant differences in average CNC scores at two years: those implanted in the left had an average CNC score of $52.4 \%$ whereas those implanted on the right had an average CNC score of $51.5 \%$ ( $p=$ $0.73)$.

\section{Discussion}

Patients in this study experienced a significant improvement in audiologic performance post-CI as seen with CNC word scores $(p<0.05)$. This is in accordance with data from other studies showing significant improvement in both speech and word scores in the adult population [17]-[25]. The complication rate was similar to that reported in other studies with only two wound infections and other minor complications; there have been multiple prior studies demonstrating that surgical complications are a rarity even in this adult age group [19] [26] [27].

There has been much deliberation about the effect of age at implantation versus duration of hearing loss on speech perception scores after CI [7] [14] [28]-[31]. Previous data show that age at implantation is significantly associated with poorer CI outcomes [14]. The reason is thought to be the association with cognitive processing required for auditory processing and decoding of the input supplied by the CI [32]. The cognitive ability to pro-

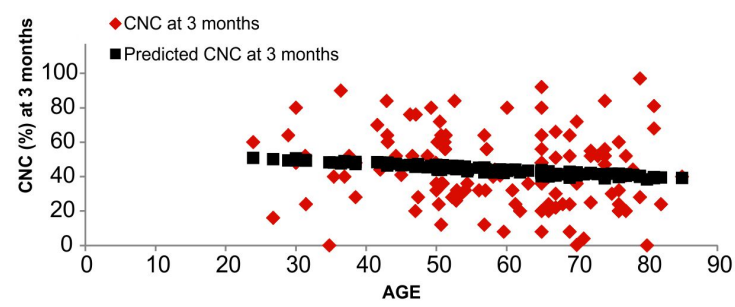

(a)

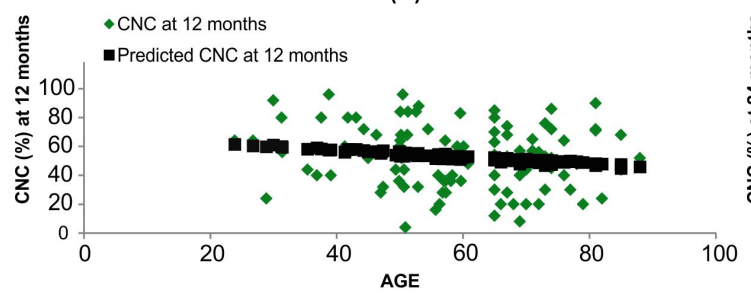

(c)

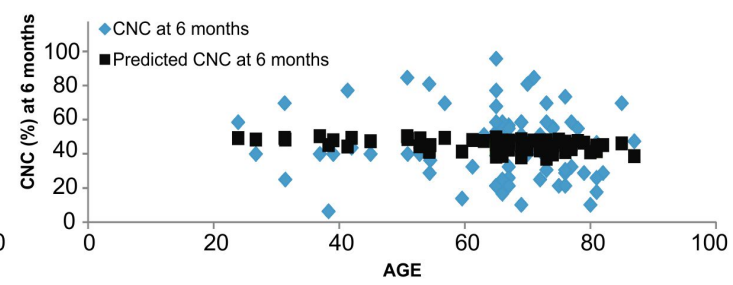

(b)

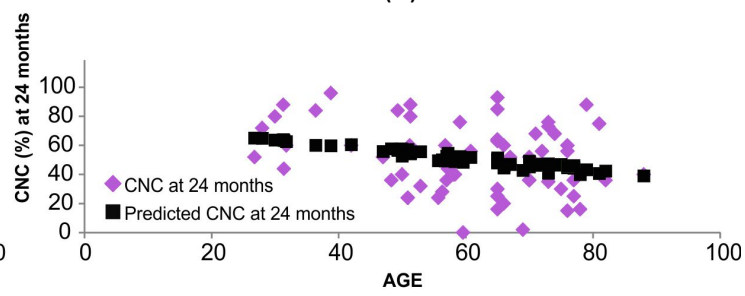

(d)

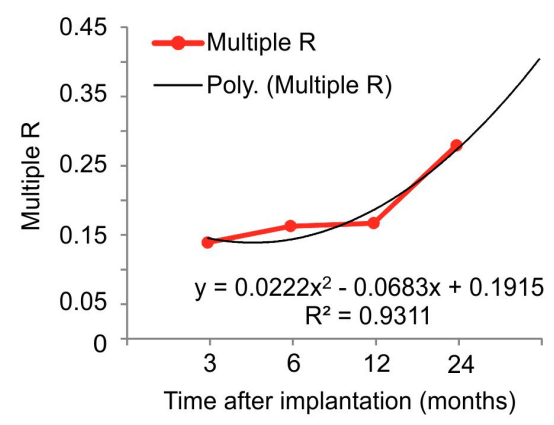

(e)

Figure 3. Multiple regression with (a) correlation between age and CNC at 3 months; (b) correlation between age and CNC at 6 months; (c) correlation between age and CNC at 12 months; (d) correlation between age and CNC at 24 months; and (e) trend curve. 


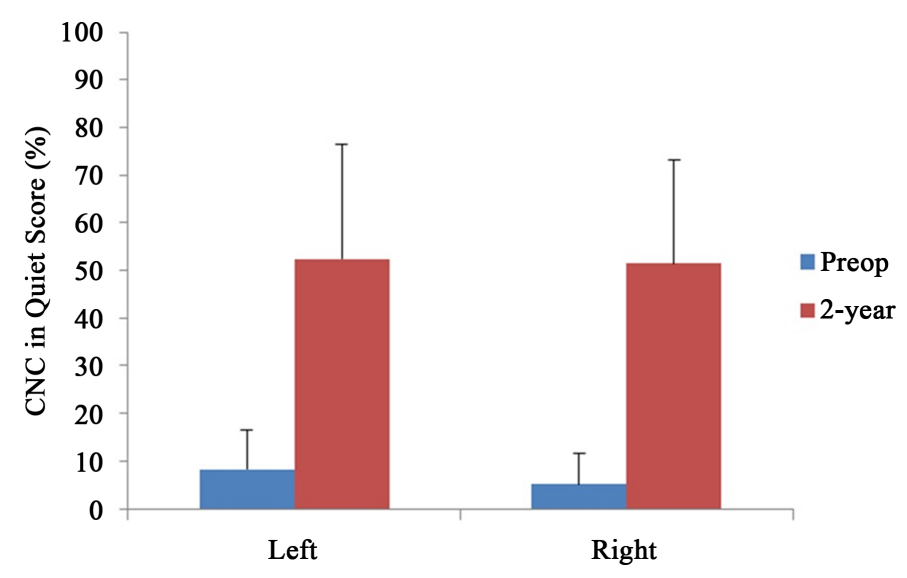

Figure 4. Pre- and 2-year postoperative speech perception scores in quiet for patients implanted in the left versus right ear.

cess and decode is thought to decline with age [33] [34]. When we stratified our age groups into younger (ages $21-64)$ and older $(65+)$, there was no statistical difference in CNC word scores at 3, 12, or 24 months postoperative. This suggests that the older group did not require a prolonged time to acclimate to the cochlear implant technology as predicted in prior studies. Perhaps there is a correlation between cognitive ability and outcomes, but older adults with good cognitive function and close follow up seemed to have significant improvement in this study. There was no mention of cognitive decline, dementia, Alzheimer's or other similar diagnoses in the charts of any of the patients that were implanted in our study.

The prior studies reporting older adult recipients attaining poorer speech perception scores compared with younger patients postoperatively were based on testing in noise [35]-[37]. This problem most likely reflects a complementary interaction between the auditory and cognitive systems. This complex environment is when cognitive decline can show its effect on outcomes. However, our study focused on CNC testing in quiet, so this was unable to be elucidated. Leung et al. found that a shorter percentage of life spent with hearing loss and residual speech recognition carry a greater predictive value in determining postoperative performance than age [7]. In contrast, we did not observe such a clear correlation between duration of deafness and outcomes post-implant, as has other studies [25] [38] [39]. However, this can also be due to the fact that this was a retrospective study relying on self-reported duration of hearing loss. Authors have used a variety of methods to delineate the timeframe of hearing loss in retrospective studies. For example, Rubinstein et al. asked patients when they stopped being able to use the telephone in the ear to be implanted [9]. This is one unfortunate limitation for retrospective reviews of charts. It should be clarified, as well, that studies in the literature tend to emphasize duration of profound hearing loss as opposed to duration of any form of hearing loss. Patients typically are able to remember more accurately the transition to a profound hearing loss wherein they lose functionality such as being able to talk on the telephone.

Duration of deafness has been shown to have a negative correlation with post-implant performance in a number of studies [40]. Multiple authors and institutions have contributed predictive models for post-implant outcomes, typically using duration of deafness as a primary variable. Several other authors, however, have found no correlation or only a weak correlation between duration of deafness and postoperative performance [40]-[42]. For example, Waltzman et al. studied the relationship between preoperative factors and two-year postoperative performance in 82 patients at the Department of Veterans Affairs and noted only a weak correlation with length of deafness and postoperative performance [41]. Hamzavi et al. drew a similar conclusion, noting duration of deafness did not appear to have relevant effects on the final outcome [42]. Moreover, there is high variability in the coefficient of determination and correlation coefficient (i.e., $\mathrm{R}^{2}$ and $\mathrm{r}$ ) data seen in prior studies that attempt to support duration of deafness as being significant.

Our data similarly hint at a weak correlation between outcome and duration of deafness. The correlation coefficient of 0.27 indicates that there was no definitive connection between variables at all. It is difficult to draw universal conclusions about duration of deafness across studies because information is typically acquired via patient report, which relies on patient memory for historical accuracy. This is (like in most reports) a limitation of 
our study and data set. It appears the literature is not conclusive as to the clinical significance that duration of deafness plays in CI, and our data support the notion that a lengthy duration of deafness in postlingually deafened adults is not a contraindication for implantation.

This study has clinical implications in the setting of counseling postlingually deafened adults regarding the therapeutic options for hearing restoration. While hearing aid amplification may be appropriate for people with mild to moderate hearing loss, adults with severe to profound sensorineural hearing loss should be made aware of the benefits along with potential risks of CI. Most clinicians now agree that age should not be an excluding factor when choosing candidates for cochlear implantation. The fact that this type of surgery is well-tolerated requires a short operative time, and causes minimal blood loss is advantageous to the senior population. Rather than basing the decision of surgery on years of life or duration of deafness, a multidisciplinary approach to adequately assess eligibility should be employed. Indeed, further studies are needed to better understand how this multifactorial process is impacted by the numerous factors to predict postoperative outcomes.

\section{Conclusion}

Our findings suggest that cochlear implantation in both age groups is equally effective in improving speech scores. We did not observe a clear correlation between duration of deafness and post-implant speech outcomes. However, further research using a uniform definition constituting duration of deafness is needed to better understand how it affects outcomes.

\section{Acknowledgements}

We would like to thank Dr. Ksenia Varakina for her assistance with statistical analysis.

\section{References}

[1] Stevens, G., Flaxman, S., Brunskill, E., et al. (2013) Global and Regional Hearing Impairment Prevalence: An Analysis of 42 Studies in 29 Countries. The European Journal of Public Health, 23, 146-152. http://dx.doi.org/10.1093/eurpub/ckr176

[2] Semenov, Y.R., Martinez-Monedero, R. and Niparko, J.K. (2012) Cochlear Implants: Clinical and Societal Outcomes. Otolaryngologic Clinics of North America, 45, 959-981. http://dx.doi.org/10.1016/j.otc.2012.06.003

[3] Blamey, P., Artieres, F., Başkent, D., et al. (2012) Factors Affecting Auditory Performance of Postlinguistically Deaf Adults Using Cochlear Implants: An Update with 2251 Patients. Audiology and Neurotology, 18, 36-47. http://dx.doi.org/10.1159/000343189

[4] Roditi, R.E., Poissant, S.F., Bero, E.M., et al. (2009) A Predictive Model of Cochlear Implant Performance in Postlingually Deafened Adults. Otology \& Neurotology, 30, 449-454. http://dx.doi.org/10.1097/MAO.0b013e31819d3480

[5] Lazard, D.S., Vincent, C., Venail, F., et al. (2012) Pre-, Per- and Postoperative Factors Affecting Performance of Postlinguistically Deaf Adults Using Cochlear Implants: A New Conceptual Model over Time. PloS ONE, 7, e48739. http://dx.doi.org/10.1371/journal.pone.0048739

[6] Hirschfelder, A., Gräbel, S. and Olze, H. (2008) The Impact of Cochlear Implantation on Quality of Life: The Role of Audiologic Performance and Variables. Otolaryngology—Head and Neck Surgery, 138, 357-362. http://dx.doi.org/10.1016/j.otohns.2007.10.019

[7] Leung, J., Wang, N., Yeagle, J.D., et al. (2005) Predictive Models for Cochlear Implantation in Elderly Candidates. Archives of Otolaryngology—Head \& Neck Surgery, 131, 1049-1054. http://dx.doi.org/10.1001/archotol.131.12.1049

[8] Blamey, P., Pyman, B., Gordon, C., et al. (1992) Factors Predicting Post-Operative Sentence Scores in Postlingually Deaf Adult Cochlear Implant Patients. Annals of Otology, Rhinology and Laryngology, 101, 342-348. http://dx.doi.org/10.1177/000348949210100410

[9] Rubinstein, J.T., Parkinson, W.S., Tyler, R.S. and Gantz, B.J. (1999) Residual Speech Recognition and Cochlear Implant Performance: Effects of Implantation Criteria. American Journal of Otology, 20, 445-452.

[10] UK Cochlear Implant Study Group (2004) Criteria of Candidacy for Unilateral Cochlear Implantation in Postlingually deafened Adults I: Theory and Measures of Effectiveness. Ear and Hearing, 25, 310-335. http://dx.doi.org/10.1097/01.AUD.0000134549.48718.53

[11] Gantz, B.J., Tyler, R.S., Rubinstein, J.T., Wolaver, A., Lowder, M., Abbas, P., et al. (2002) Binaural Cochlear Implants Placed during the Same Operation. Otology \& Neurotology, 23, 169-180.

http://dx.doi.org/10.1097/00129492-200203000-00012 
[12] Green, K.M.J., Bhatt, Y.M., Mawman, D.J., O’driscoll, M.P., Saeed, S.R., Ramsden, R.T. and Green, M.W. (2007) Predictors of Audiological Outcome Following Cochlear Implantation in Adults. Cochlear Implants International, 8, 111. http://dx.doi.org/10.1179/cim.2007.8.1.1

[13] Roberts, D.S., Lin, H.W., Herrmann, B.S. and Lee, D.J. (2013) Differential Cochlear Implant Outcomes in Older Adults. The Laryngoscope, 123, 1952-1956. http://dx.doi.org/10.1002/lary.23676

[14] Lin, F.R., Chien, W.W., Li, L.S., Clarrett, D.M., Niparko, J.K. and Francis, H.W. (2012) Cochlear Implantation in Older Adults. Medicine, 91, 229-239. http://dx.doi.org/10.1097/MD.0b013e31826b145a

[15] Friedman, D.R., Green, J., Fang, Y.X., Ensor, K., Roland, J.T. and Waltzman, S.B. (2015) Sequential Bilateral Cochlear Implantation in the Adolescent Population. Laryngoscope, 125, 1952-1958. http://dx.doi.org/10.1002/lary.25293

[16] Alice, B., Silvia, M., Laura, G., Patrizia, T. and Roberto, B. (2013) Cochlear Implantation in the Elderly: Surgical and Hearing Outcomes. BMC Surgery, 13, S1. http://dx.doi.org/10.1186/1471-2482-13-S2-S1

[17] Skarzynsky, P.H., Olszewsky, L., Skarzynsky, H., et al. (2012) Cochlear Implantation in the Aging Population. Audiology and Neurotology, 17, 15-17.

[18] Luntz, M., Yehudai, N., Most, T., et al. (2012) Cochlear Implantation in the Elderly: Surgical and Hearing Outcomes. Audiology and Neurotology, 17, 14-15.

[19] Huarte, A., Lezaun, R. and Manrique, M. (2014) Quality of Life Outcomes for Cochlear Implantation in the Elderly. Audiology and Neurotology, 19, 36-39. http://dx.doi.org/10.1159/000371608

[20] Poissant, S.F., Beaudoin, F., Huang, J., Brodsky, J. and Lee, D.J. (2008) Impact of Cochlear Implantation on Speech Understanding, Depression, and Loneliness in the Elderly. Journal of Otolaryngology—Head \& Neck Surgery, 37, 488-494.

[21] Migirov, L., Taitelbaum-Swead, R., Drendel, M., Hildesheimer, M. and Kronenberg, J. (2010) Cochlear Implantation in Elderly Patients: Surgical and Audiological Outcome. Gerontology, 56, 123-128. http://dx.doi.org/10.1159/000235864

[22] Chatelin, V., Kim, E.J., Driscoll, C., Larky, J., Polite, C., Price, L. and Lalwani, A.K. (2004) Cochlear Implant Outcomes in the Elderly. Otology \& Neurotology, 25, 298-301. http://dx.doi.org/10.1097/00129492-200405000-00017

[23] Eshraghi, A.A., Rodriguez, M., Balkany, T.J., Telischi, F.F., Angeli, S., Hodges, A.V. and Adil, E. (2009) Cochlear Implant Surgery in Patients More than Seventy-Nine Years Old. Laryngoscope, 119, 1180-1183.

http://dx.doi.org/10.1002/lary.20182

[24] Francis, H.W., Chee, N., Yeagle, J., Cheng, A. and Niparko, J.K. (2002) Impact of Cochlear Implants on the Functional Health Status of Older Adults. Laryngoscope, 112, 1482-1488. http://dx.doi.org/10.1097/00005537-200208000-00028

[25] Kelsall, D.C., Shallop, J.K. and Burnelli, T. (1995) Cochlear Implantation in the Elderly. American Journal of Otolaryngology, 16, 609-615.

[26] Jeppesen, J. and Faber, C.E. (2013) Surgical Complications Following Cochlear Implantation in Adults Based on a Proposed Reporting Consensus. Acta Oto-Laryngologica, 133, 1012-1021. http://dx.doi.org/10.3109/00016489.2013.797604

[27] Cohen, N.L. and Hoffman, R.A. (1991) Complications of Cochlear Implant Surgery in Adults and Children. Annals of Otology, Rhinology \& Laryngology, 100, 708-711. http://dx.doi.org/10.1177/000348949110000903

[28] Carlson, M.L., Breen, J.T., Gifford, R.H., Driscoll, C.L., Neff, B.A., Beatty, C.W., et al. (2010) Cochlear Implantation in the Octogenarian and Nonagenarian. Otology \& Neurotology, 31, 1343-1349.

[29] Chan, V., Tong, M., Yue, V., Wong, T., Leung, E., Yuen, K. and van Hasselt, A. (2007) Performance of Older Adult Cochlear Implant Users in Hong Kong. Ear and Hearing, 28, 52S-55S.

[30] Migirov, L., Taitelbaum-Swead, R., Drendel, M., Hildesheimer, M. and Kronenberg, J. (2010) Cochlear Implantation in Elderly Patients: Surgical and Audiological Outcome. Gerontology, 56, 123-128.

[31] Vermeire, K., Brokx, J.P., Wuyts, F.L., Cochet, E., Hofkens, A. and Van de Heyning, P.H. (2005) Quality-of-Life Benefit from Cochlear Implantation in the Elderly. Otology \& Neurotology, 26, 188-195.

[32] Tun, P.A., McCoy, S. and Wingfield, A. (2009) Aging, Hearing Acuity, and the Attentional Costs of Effortful Listening. Psychology and Aging, 24, 761-766.

[33] Salthouse, T.A. (2000) Aging and Measures of Processing Speed. Biological Psychology, 54, 35-54.

[34] Salthouse, T.A. (1996) The Processing-Speed Theory of Adult Age Differences in Cognition. Psychological Review, 103, 403-428.

[35] Sanchez-Cuadrado, I., Lassaletta, L., Perez-More, R.M., Zernotti, M., Di Gregorio, M.F., Boccio, C. and Gavilán, J. (2013) Is There an Age Limit for Cochlear Implantation? Annals of Otology, Rhinology, \& Laryngology, 122, $222-228$. 
http://dx.doi.org/10.1177/000348941312200402

[36] Schneider, B.A., Pichora-Fuller, K. and Daneman, M. (2010) Effects of Senescent Changes in Audition and Cognition on Spoken Language Comprehension. In: Gordon-Salant, S., et al., Eds., The Aging Auditory System, Springer, New York, 167-210. http://dx.doi.org/10.1007/978-1-4419-0993-0_7

[37] Holden, L.K., Finley, C.C., Firszt, J.B., Holden, T.A., Brenner, C., Potts, L.G., et al. (2013) Factors Affecting OpenSet Word Recognition in Adults with Cochlear Implants. Ear \& Hearing, 43, 342-360. http://dx.doi.org/10.1097/AUD.0b013e3182741aa7

[38] Sterkers, O., Mosnier, I., Ambert-Dahan, E., Herelle-Dupuy, E., Bozorg-Grayeli, A. and Bouccara, D. (2004) Cochlear Implants in Elderly People: Preliminary Results. Acta Oto-Laryngologica, 124, 64-67. http://dx.doi.org/10.1080/03655230410017184

[39] Lachowska, M., Pastuszka, A., Glinka, P. and Niemczyk, K. (2013) Is Cochlear Implantation a Good Treatment Method for Profoundly Deafened Elderly? Clinical Interventions of Aging, 8, 1339-1346. http://dx.doi.org/10.2147/CIA.S50698

[40] Van Dijk, J.E., van Olphen, A.F., Mens, L.H., Brokx, J.P., van den Broek, P. and Smoorenburg, G.F. (1995) Predictive Factors for Success with a Cochlear Implant. Annals of Otology, Rhinology \& Laryngology, 166, 196-198.

[41] Waltzman, S.B., Fisher, S.G., Niparko, J.K. and Cohen, N.L. (1995) Predictors of Postoperative Performance with Cochlear Implants. Annals of Otology, Rhinology \& Laryngology, 165, 15-18.

[42] Hamzavi, J., Baumgartner, W.D., Pok, S.M., Franz, P. and Gstoettner, W. (2003) Variables Affecting Speech Perception in Postlingually Deaf Adults Following Cochlear Implantation. Acta Oto-Laryngologica, 123, 493-498. http://dx.doi.org/10.1080/0036554021000028120 